\title{
Assessment of levels of moderate-to-vigorous physical activity in physical education classes using 3-dimensional accelerometer: Competition domain
}

\author{
Gyu-Il Lee* \\ Kyungpook National University
}

\begin{abstract}
[Purpose] The purpose of this study was to investigate characteristics of levels of physical activity in considering gender and different types of competition-oriented physical activity classes using threedimensional accelerometers. [Methods] A total of 981 students(505 male students, 476 female students) in six different types of physical education classes were participated in this study. All of the six different types of physical education classes were competition-oriented classes, and levels of physical activity were accessed by three-dimensional accelerometers. Data were analyzed using t-test and ANOVA. [Results] First, descriptive analyses of participation time of levels of physical activity showed that MVPA of physical education classes is 10.26 mins $(22.89 \%)$ on average, and, MVPA showed differently in different types of physical education classes in the order of $\mathrm{T}$ ball(14.61 mins), flying disk(12.61 mins), soccer(10.78 mins), volley ball(10.56 mins), basketball( $9.64 \mathrm{mins})$, and table tennis(5.73 mins). Second, female students showed significantly lower levels of MVPA in all the different types of physical education classes. Third, post-hoc analyses showed that significantly higher levels of MVPA were found in T ball physical education classes and significantly lower levels of MVPA were found in table tennis physical education classes, compared to other types of physical education classes. [Conclusions] MVPA in physical education classes is not satisfied with recommended MVPA, and MVPA in Korean physical education classes is lower than MVPA in same types of physical education classes in other countries. In addition, significant mean differences of MVPA are found between male and female students, and new sports physical education classes show higher levels of MVPA compared to classic sports physical education classes. These results indicate that competition oriented physical education classes widely used in Korea need to find ways to increase MVPA and to overcome different levels of MVPA between male and female students.
\end{abstract}

Key words: Physical education, Middle school girl, Competition domain, Moderate to vigorous physical activity, Three-dimensional accelerometer

\section{서 론}

건강발달을 목표로 하는 청소년기에는 중-고강도 신

논문 투고일: 2018. 11. 22 .

논문 수정일: 2019. 01. 03 .

게재 확정일: 2019. 02. 07

* 교신저자 : 이규일(mauri94@knu.ac.kr).

* 이 논문은 2017년 대한민국 교육부와 한국연구재단의 지원을

받아 수행된 연구임(NRF-2017S1A5A2A01025633).
체활동 (moderate to vigorous physical activity, 이하 MVPA)이 강조된다(Trost \& Loprinzi, 2008). MVPA 는 대사당량 (Metabolic Equivalent Task, MET) 기준 으로 $3 \sim 6 \mathrm{METs}$ (예, 빠르게 걷기, 탁구나 테니스 복식, 춤추기 등)의 중강도 운동과 $6 \mathrm{METs}$ 이상 (예, 탁구나 테 니스 단식, 달리기 등)의 고강도 운동을 포괄하는 신체활 동이다(ACSM, 2014; CPPSE, 2013). 청소년기 MVPA 는 성인병 관련 질환(지방 과다증, 심혈관계 질환, 천식 
등)이나 심리적 문제 (불안, 우울 등) 등을 예방할 뿐만 아 니라 건강한 신체(근골격 발달 및 체력), 심리(신체적 자 기효능감, 신체활동 즐거움, 자기 개념 등), 사회(교우관 계 개선 등), 행동(라이프스타일 개선 등) 발달에 기여한다 (Bailey, 2006; Strong et al., 2005). 이에 따라, MVPA 측면에서 청소년기 신체활동 권장기준(일일 MVPA 60 분)을 제시하며(CPPSE, 2013; PAGAC, 2008), 기준 달성을 위한 방안을 다각적으로 모색하고 있다.

체육수업은 청소년기 MVPA 권장 기준 달성을 위한 중요한 활동 영역이다. 이는, 첫째, 다른 어떤 영역에서보 다 전문성과 책임감이 높은 체육교사에 의해 운영되고, 둘째, 인종이나 성, 사회경제학적 위치와 무관하게 공평 한 신체활동 참여 기회를 제공하기 때문에, 양질의 신체 활동을 제공할 수 있기 때문이다(Fairclough \& Stratton, 2006). 실제로 체육수업이 있는 날과 없는 날의 MVPA 를 비교한 McKenzie(2001)에 따르면, 체육수업이 있는 날에 청소년들의 MVPA가 의미 있게 높고, 체 육수업의 영 향력은 운동강도와 연령이 높아질수록 증가한다. 또한 심 박수를 분석한 연구들(Dale et al., 2000; Gavarry et al., 1997)은 체육수업 시간이 하루 중 가장 높은 심박수를 기록한다고 보고한다. 따라서, 체육수업 MVPA에 관심을 기울일 필요가 있다.

미국의 청소년 건강당국은 Healthy People 2010 프 로젝트의「목표 22-10」을 통해 체육수업의 MVPA 비중 을 '수업시간 대비 $50 \%$ 이상'으로 명시하고 있다(CPPSE, 2013). 이러한 체육수업의 MVPA 권장 기준은 일일 MVPA 권장 기준을 달성하기 위해 산술적으로 필요한 체육수업의 $\mathrm{MVPA}$ 시간을 산정한 것으로, 신체적으로 적극적인 체육수 업의 상징적 기준으로 적용되고 있다(NASPE, 2005). 그 러나 실제 체육수업의 MVPA 수준은 권장 기준을 달성하 지 못하고 있다. 초·중등학교 체육수업의 MVPA 분석 연 구들을 종합한 연구들은 초등학교(Fairclough \& Stratton, 2006)와 중학교(Fairclough \& Stratton, 2005a) 체육 수업의 MVPA 수준을 각각 $34.2 \%$ 와 $27 \sim 47 \%$ 로 밝히 고 있다. 이들 연구들은 체육수업의 MVPA 수준을 실증 하는 동시에 MVPA 측면에서 체육수업의 문제를 밝히며 (Fairclough \& Stratton, 2005a, 2006; Pate et al., 2011), 신체적으로 보다 적극적인 체육수업으로 나아갈 방향을 제시해 주고 있다.

반면, 우리나라 체육교육 분야에서는 신체활동의 가치 즉 질(質)의 측면에서 체육교육을 바라보고 있다. 구체적
으로, 체육교육의 실천 영역을 안내하는 체육과 교육과 정 문서는 2007 수정 문서부터 신체활동 가치를 내면화 하고 실천하는 것을 체육과 교육의 목표로 삼아 왔으며, 가치를 근간으로 내용체계를 개발해 왔다. 체육교육의 연 구 영역에서도 질적연구의 시대로 선언할 만큼 체육교육 의 성과를 질적 측면에서 확인해 왔다(Choi, 2001). 이 로 인해, 신체활동의 양적 관점에서 체 육수업의 문제를 파악하고 개선하기 위한 노력은 간과되어 왔으며, 그 결 과, 체육수업이 제공하는 신체활동의 양적 지표에 대한 실 태조차 파악하지 못하고 있다. 이러한 측면에서, 국내 체 육수업의 신체활동 실태를 파악하고, 이를 토대로 체육수 업의 신체활동을 증진시킬 수 있는 교육적 방안을 다각적 으로 모색할 필요가 있다.

한편, 체육수업 MVPA는 종목에 따라 차이를 보인다. 연구들은 스포츠 활동, 체력운동, 움직임 활동(체조, 무용) 순으로 보고하고 있다(Arnett \& Lutz, 2003; Fairclough, 2003; Scantling et al., 1998; Strand \& Anderson, 1996). 우리나라 체육과 교육과정에서는 스포츠 활동을 경쟁영역 (competition domain)으로 다루고 있다. 또한 최 근 학교 현장에서는 뉴스포츠(new sports) 활동이 활발 히 적용되고 있다. 뉴스포츠 활동은 학습 만족도나 학습 참여 기회를 높인다는 점에서 전통 스포츠(classic sports) 의 대안으로 모색되고 있다(Griggs, 2012; Kim, 2009; 2010). 이에, 본 연구에서는 첫째, 경쟁영역 (근대 스포츠, 뉴스포츠)을 중심으로 체육수업의 신체활동 특성을 살펴 보고자 하였다.

둘째, 청소년기 신체활동은 성별에 따른 차이를 보인다. 청소년 건강 백서 형식으로 발간된 $\operatorname{CPPSE}(2013)$ 는 청 소년기 신체활동에 영향을 미치는 인구통계학적 요인들 (예, 성 : 남>여, 연령과 $\mathrm{BMI}$ : 반비례, 인종: 백인 >히스 패닉 $>$ 흑인) 중 성 (sex)에 의한 차이가 가장 보편적이고 현저한 차이를 보이는 변인으로 밝히고 있다. 체육수업 신체활동 특성을 보고한 연구들 역시 남학생의 MVPA가 여학생보다 높다고 밝히고 있다(Fairclough \& Stratton, $2005 \mathrm{a}, 2006)$. 따라서 본 연구에서는 체 육수업 신체활 동의 성별 특성을 분석하고자 하였다.

셋째, 측정도구 측면에서, 전통적으로 신체활동 측정 은 심박수계, 직접 관찰법의 일환인 SOFIT(System for Observing Fitness Instruction Time), 1차원 가속도계 등을 활용해 측정되어 왔다. Welk(2002)에 따르면, 심 박수계는 동시 측정 인원과 정서적 변화에 따른 심박수 
의 변화를 제거하지 못한다는 약점이 있고, SOFIT은 측 정자의 주관적 판단이 개입될 소지가 크다. 실제로 $\mathrm{SOFIT}$ 은 MVPA 값 자체의 측정오류에 대한 지적이 제기되어 왔다(McClain et al., 2008). 이에 비해 가속도계는 대규 모 측정이 용이하고 기계 착용으로 인한 활동 제약 문제 가 상대적으로 적은 강도별 신체활동량에 대한 타당하 고 신뢰할 만한 결과를 제공하는 신체활동 측정도구이다 (Tudor-Locke et al., 2011; Welk, 2002). 특히 최근 개량 된 3차원 가속도계는 움직임을 세 축으로 분석해 보다 객 관적인 측정 결과를 제공하는 측정도구로 평가되고 있다 (Lee, 2012). 이에, 본 연구에서는 3차원 가속도계를 활 용해 체육수업 MVPA 실태를 파악하고자 하였다.

따라서 본 연구의 목적은 3 차원 가속도계를 활용해 경쟁 영역 체육수업의 MVPA 특성을 성과 종목 측면에서 파악 하는데 있다. 이를 달성하기 위한 연구 질문은 다음과 같다.

첫째, 경쟁영역 체육수업의 MVPA 수준은 어떠한가?

둘째, 경쟁영역 체육수업의 MVPA 수준은 성별에 따 라 차이를 보이는가?

셋째, 경쟁영역 체육수업의 MVPA 수준은 활동 종목 에 따라 차이를 보이는가?

\section{연구방법}

\section{연구 대상}

$\mathrm{D}$ 시 소재 6 개 중학교를 연구학교로 선정하였다. 각 학교마다 한 종목으로 운영된 체육수업의 신체활동량을 측정하였다. 측정된 체육수업 종목을 살펴보면, 첫째, 활 동 종목은 2015 체육과 교육과정을 근거로 경쟁활동의 세 영역인 영역형 경쟁활동(축구, 농구, 플라잉 디스크), 네트형 경쟁활동(배구, 탁구), 필드형 경쟁활동(티볼)으
로 구분해 선정되었다. 둘째, 근대와 뉴스포츠 측면에서, 각각 4종목(축구, 농구, 배구, 탁구)과 2종목(플라잉 디 스크, 티볼)으로 선정하였다. 셋째, 종목 간 및 종목 내의 차시별 교수·학습 방법을 통제하기 위해 모든 수업을 기 능중심수업 방법으로 운영하였다. 기능중심수업의 한 차 시는 기능 시범(Demonstration), 기능에 대한 설명 (Explanation), 기능 연습(Practice)으로 운영되는 수업으 로 정의된다(Kirk, 2010). 특히 기능중심수업은 교사 주 도로 이루어지기 때문에 자유 놀이(free play)가 허용되 지 않으며, 기능을 낮은 수준에서부터 순차적으로 가르치 기 때문에 게임 활동은 단원의 마지막 단계에 제 공된다는 특성이 있다. 이에 자유 놀이 활동과 함께 게임 활동 역시 통제되었다.

편의표집 방법을 활용해 연구 대상을 선정하였다. 학교 와 종목별로 선정된 연구대상의 수는 $\mathrm{A}$ 학교(축구, 23 명* 6학급), B학교(농구, 27명*6학급), C학교(배구, 22명*7학 급), $\mathrm{E}$ 학교(플라잉 디스크, 27명*6학급), F학교(탁구, 29 명*8학급), $\mathrm{G}$ 학교(티볼, 26명*6학급)의 총 1,004명 (남학 생 518 명, 여학생 486명)이며, 측정 오류가 발생한 23명 의 자료를 제외한 981 명 (남 505명, 여 476명)의 자료를 분석에 활용하였다. 연구 대상의 특성은 〈Table 1)과 같다.

\section{측정도구 및 방법}

본 연구에서는 ActiGraph 사에서 개발한 3차원 가속 도계 (GT3X)를 활용해 신체활동을 측정하였다. 측정은 6 개 연구학교에서 각 종목으로 운영된 체육수업에 참여한 남녀 학생을 대상으로 이루어졌다(Table 1 참조). 3 차원 가속도계 측정은 학급별로 수업 당 1 회 이루어졌으며, 종 목별 수업 활동의 동질성을 유지하기 위해 패스 활동(축구: 패스, 배구: 언더 \& 오버 패스, 농구: 체스트 패스, 티볼: 던지기와 받기, 플라잉디스크: 던지기와 받기, 탁구: 스트 로크로 주고받기)을 과제로 삼은 수업에서 이루어졌다. 측

Table 1. Characteristics of research participants

\begin{tabular}{lcccccccc}
\hline \hline & \multicolumn{9}{c}{ Content } & Height $(\mathrm{cm})$ & Weight $(\mathrm{kg})$ \\
\cline { 2 - 7 } & Soc & Bas & Vol & Fly & Tab & T & & \\
\hline Male $(N=505)$ & 72 & 78 & 86 & 84 & 102 & 83 & $166.63( \pm 7.06)$ & $61.70( \pm 14.08)$ \\
\hline Female $(N=476)$ & 58 & 84 & 68 & 70 & 127 & 69 & $158.93( \pm 5.35)$ & $53.49( \pm 10.72)$ \\
\hline Total $(N=981)$ & 130 & 162 & 154 & 154 & 229 & 152 & $162.90( \pm 7.37)$ & $57.72( \pm 13.21)$ \\
\hline \hline
\end{tabular}

soc: soccer, bas: basketball, vol: volleyball, fly: flying disk, tab: table tennis, T: $\mathrm{T}$ ball 
정을 위해, 연구자는 교사로부터 미리 건네받은 연구 대상 의 키와 몸무게 정보를 3차원 가속도계에 입력하는 동시 에 해당 수업 시간에 맞춰 기계를 세팅하였다. 세팅된 가속 도계를 수업 전 쉬는 시간에 학생들의 배꼽 아래 $3 \mathrm{~cm}$ 부 위에 착용시켰으며, 이때 임의로 가속도계를 풀지 말 것, 평 소와 다른 수업행 동을 하지 말 것 등의 주의사항을 알렸다.

\section{자료 분석}

수업이 종료되면, 가속도계에 측정된 자료를 ActiGraph 사에서 제공하는 신체활동 분석 프로그램에 입력해, 45 분 동안 이루어진 강도별 (비활동, 저강도, 중강도, 고강도 활 동) 신체활동 시간과 비중을 분석하였다. 이때 강도별 신 체활동 기준(cut-point)은 Puyau Children(2005)을 활 용하였다. 엑셀 파일로 변환된 자료를 통계프로그램(SPSS for win. 23.0)에 입력해, 성별 분석을 위해 독립 표본 t 검정과 종목별 비교를 위해 one-way ANOVA를 실시하 였으며, 사후검증으로 LSD 방법을 사용하였다. 통계적 유 의 수준은 .05 이하로 하였다(Welk, 2002).

\section{연구결과}

\section{경쟁영역 체육수업의 MVPA}

체육수업의 신체활동 시간을 살펴보면, 전체 학생의 운 동강도별 시간은 가벼운 활동(17.81분), 좌식활동 (16.78 분), MVPA(10.26분)으로 나타났다. 전체 수업 시간 대 비 비중은 각각 $39.72 \%, 37.39 \%, 22.89 \%$ 로 나타났다. MVPA 측면에서 우리나라 남녀 중학생은 권장 기준(전 체 수업시간의 $50 \%$ 이상)에 미달하는 것으로 확인되었다. 남학생의 경우, 가벼운 활동 (18.21분, $40.60 \%)$ 이 가장 높았고, 좌식활동(13.83분)과 MVPA(12.80분) 비중은 $30.82 \%, 28.58 \%$ 로 나타났다. 여학생의 경우, 좌식활동 의 비중 $(44.37 \%)$ 이 가장 높았고, 가벼운 활동 $(38.78 \%)$ 과 MVPA(16.85\%) 순으로 나타났다(Table 2 참조).

종목별 MVPA 수준을 살펴보면, 전체 학생의 MVPA 수준은 티볼(14.61분), 플라잉 디스크(12.61분), 축구 (10.78분), 배구(10.56분), 농구(9.64분), 탁구(5.73분) 순으로 나타났다. 남학생의 경우, 티볼(16.96분), 플라잉 디스크(16.52분), 축구(12.86분), 농구(12.29분), 배구
(11.66분), 탁구(7.69분) 순으로 높았고, 여학생은 티볼 (11.78분), 배구(9.18분), 축구(8.19분), 플라잉 디스크 (7.91분), 농구(7.18분), 탁구(4.16분) 순으로 나타났다 (Table 4 참조).

전통 스포츠(축구, 농구, 배구, 탁구)와 뉴스포츠(티볼, 플라잉 디스크)의 MVPA 수준은 〈Table 6〉에 제시되어 있다. 남학생의 MVPA 참여 시간은 전통 스포츠(10.86 분)와 뉴스포츠(16.74분)에서 나타났고, 여학생은 각각 6.62 분과 9.83 분으로 나타났다.

\section{성에 따른 경쟁영역 체육수업의 MVPA}

여학생의 좌식활동 비중은 남학생에 비해 유의하게 높 은 값을 보였다 $(p<.001)$. 여학생의 가벼운 활동 비중은 남학생에 비해 유의하게 낮은 값을 나타냈다 $(p<.05)$. 여 학생의 MVPA 비중은 남학생에 비해 유의하게 낮은 값을 나타냈다( $p<.001)$ (Table 3 참조).

Table 2. Participation time of levels of physical activity in P.E. classes

(Mean $\pm \mathrm{SD})$

\begin{tabular}{lcccccc}
\hline \hline & \multicolumn{2}{c}{ Sedentary } & \multicolumn{2}{c}{ Light } & \multicolumn{2}{c}{ MVPA } \\
\cline { 2 - 7 } & $\begin{array}{c}\text { Time } \\
(\mathrm{min})\end{array}$ & $\%$ & $\begin{array}{c}\text { Time } \\
(\mathrm{min})\end{array}$ & $\%$ & $\begin{array}{c}\text { Time } \\
(\mathrm{min})\end{array}$ & $\%$ \\
\hline $\begin{array}{l}\text { Male } \\
(N=505)\end{array}$ & $\begin{array}{c}13.83 \\
( \pm 7.64)\end{array}$ & $\begin{array}{c}30.82 \\
( \pm 16.94)\end{array}$ & $\begin{array}{c}18.21 \\
( \pm 4.97)\end{array}$ & $\begin{array}{l}40.60 \\
( \pm 11.02)\end{array}$ & $\begin{array}{c}12.80 \\
( \pm 6.07)\end{array}$ & $\begin{array}{c}28.58 \\
( \pm 13.60)\end{array}$ \\
\hline $\begin{array}{l}\text { Female } \\
(N=476)\end{array}$ & $\begin{array}{c}19.91 \\
( \pm 7.99)\end{array}$ & $\begin{array}{c}44.37 \\
( \pm 17.67)\end{array}$ & $\begin{array}{c}17.39 \\
( \pm 5.46)\end{array}$ & $\begin{array}{c}38.78 \\
( \pm 12.15)\end{array}$ & $\begin{array}{c}7.56( \pm 4 \\
55)\end{array}$ & $\begin{array}{c}16.85 \\
( \pm 10.12)\end{array}$ \\
\hline $\begin{array}{l}\text { Total } \\
(N=981)\end{array}$ & $\begin{array}{c}16.78 \\
( \pm 8.38)\end{array}$ & $\begin{array}{c}37.39 \\
( \pm 18.57)\end{array}$ & $\begin{array}{c}17.81 \\
( \pm 5.23)\end{array}$ & $\begin{array}{c}39.72 \\
( \pm 11.61)\end{array}$ & $\begin{array}{c}10.26( \pm 5 \\
.99)\end{array}$ & $\begin{array}{c}22.89 \\
( \pm 13.39)\end{array}$ \\
\hline \hline
\end{tabular}

Table 3. Mean differences of participation ratio of levels of physical activity in P.E. classes between male and female students

\begin{tabular}{lcccc}
\hline \hline Intensity & Sex & Mean $(\%)( \pm \mathrm{SD})$ & $t$ & $p$ \\
\hline \multirow{2}{*}{ Sedentary } & Male & $30.82( \pm 16.92)$ & & \\
& Female & $44.38( \pm 17.67)$ & & $.000^{* * *}$ \\
\cline { 2 - 3 } Light & Male & $40.6( \pm 11.02)$ & & \\
\cline { 2 - 3 } & Female & $38.78( \pm 12.15)$ & & $.014^{*}$ \\
\hline \multirow{2}{*}{ MVPA } & Male & $28.59( \pm 13.66)$ & & \\
\cline { 2 - 3 } & Female & $16.85( \pm 109.12)$ & & $.000^{* * *}$ \\
\hline${ }^{*}<.05{ }^{* * *}<.001$ & & &
\end{tabular}




\section{종목에 따른 경쟁영역 체육수업의 MVPA}

종목별 남녀의 운동강도별 차이는 〈Table 4〉에 제시되 어 있다. 여학생의 좌식활동 시간은 배구를 제외한 모든
종목에서 남학생에 비해 높은 값을 나타냈다 $(p<.001)$. 농구 종목에서 남학생의 가벼운 활동 참여시간은 여학생 에 비해 유의하게 높은 값을 나타냈다( $p<.05)$. MVPA 참 여 시간은 모든 종목에서 성별에 따라 유의한 차이를 나

Table 4. Mean differences of participation time of levels of physical activity in different types of P.E. classes between male and female students

\begin{tabular}{|c|c|c|c|c|c|}
\hline \multirow{2}{*}{ Content } & \multirow{2}{*}{ Intensity } & \multicolumn{2}{|c|}{$\mathrm{M}(\min )( \pm \mathrm{SD})$} & \multirow{2}{*}{$t$} & \multirow{2}{*}{$p$} \\
\hline & & Male & Female & & \\
\hline \multirow{3}{*}{$\begin{array}{l}\text { Soccer } \\
\left(72^{1}, 58^{2}\right)\end{array}$} & Sedentary & $13.66( \pm 5.94)$ & $17.90( \pm 6.04)$ & -4.015 & $.000^{* * *}$ \\
\hline & Light & $18.48( \pm 4.57)$ & $18.91( \pm 5.09)$ & -.503 & .616 \\
\hline & MVPA & $12.86( \pm 6.03)$ & $8.19( \pm 3.95)$ & 5.077 & $.000^{* * *}$ \\
\hline \multirow{3}{*}{$\begin{array}{l}\text { Basketball } \\
\left(78^{1}, 84^{2}\right)\end{array}$} & Sedentary & $13.04( \pm 5.37)$ & $19.89( \pm 6.85)$ & -7.040 & $.000^{* * *}$ \\
\hline & Light & $19.67( \pm 4.35)$ & $17.93( \pm 5.27)$ & 2.282 & $.024^{*}$ \\
\hline & MVPA & $12.29( \pm 4.08)$ & $7.18( \pm 3.33)$ & 8.759 & $.000^{* * *}$ \\
\hline \multirow{3}{*}{$\begin{array}{l}\text { Flying disk } \\
\left(84^{1}, 70^{2}\right)\end{array}$} & Sedentary & $11.47( \pm 3.92)$ & $20.45( \pm 6.50)$ & -10.556 & $.000^{* * *}$ \\
\hline & Light & $16.13( \pm 3.40)$ & $15.76( \pm 4.31)$ & .588 & .557 \\
\hline & MVPA & $16.52( \pm 4.94)$ & $7.91( \pm 3.43)$ & 12.323 & $.000^{* * *}$ \\
\hline \multirow{3}{*}{$\begin{array}{l}\text { Volleyball } \\
\left(86^{1}, 68^{2}\right)\end{array}$} & Sedentary & $14.67( \pm 7.68)$ & $16.56( \pm 7.11)$ & -1.566 & .119 \\
\hline & Light & $18.67( \pm 5.25)$ & $19.26( \pm 5.22)$ & -.698 & .486 \\
\hline & MVPA & $11.66( \pm 5.27)$ & $9.18( \pm 4.79)$ & 3.021 & $.003^{* *}$ \\
\hline \multirow{3}{*}{$\begin{array}{l}\text { Table Tennis } \\
\left(102^{1}, 127^{2}\right)\end{array}$} & Sedentary & $19.40( \pm 9.63)$ & $25.22( \pm 7.77)$ & -5.063 & $.000^{* * *}$ \\
\hline & Light & $17.91( \pm 6.32)$ & $15.70( \pm 5.95)$ & 2.719 & $.007^{* *}$ \\
\hline & MVPA & $7.69( \pm 4.92)$ & $4.16( \pm 3.01)$ & 6.682 & $.000^{* * *}$ \\
\hline \multirow{3}{*}{$\begin{array}{l}\text { T ball } \\
\left(83^{1}, 69^{2}\right)\end{array}$} & Sedentary & $9.38( \pm 6.64)$ & $14.62( \pm 7.55)$ & -4.553 & $.000^{* * *}$ \\
\hline & Light & $18.61( \pm 4.42)$ & $18.40( \pm 5.14)$ & .275 & .783 \\
\hline & MVPA & $16.96( \pm 5.51)$ & $11.78( \pm 4.90)$ & 6.067 & $.000^{* * *}$ \\
\hline
\end{tabular}

${ }^{1}$ number of male, ${ }^{2}$ number of female

* $<.05,{ }^{* *}<.01,{ }^{* * *}<.001$

Table 5. Analysis of variance of MVPA between different types of P.E. classes

\begin{tabular}{|c|c|c|c|c|c|c|c|c|c|c|}
\hline & & \multicolumn{6}{|c|}{ Content $(\mathrm{M}(\mathrm{min}) \pm \mathrm{SD})$} & \multirow{2}{*}{$\begin{array}{c}F \\
40.857\end{array}$} & \multirow{2}{*}{$\begin{array}{c}p \\
.000^{* * *}\end{array}$} & \multirow{2}{*}{$\begin{array}{c}\text { post-hoc } \\
\mathrm{T}>\mathrm{S}, \mathrm{B}, \mathrm{V}, \mathrm{t} \\
\mathrm{F}>\mathrm{S}, \mathrm{B}, \mathrm{V}, \mathrm{t} \\
\mathrm{t}<\mathrm{S}, \mathrm{B}, \mathrm{V}, \mathrm{F}, \mathrm{T}\end{array}$} \\
\hline & Male & $\begin{array}{c}\text { Soccer } \\
(12.86 \pm 6.03)\end{array}$ & $\begin{array}{c}\text { Basketball } \\
(12.29 \pm 4.08)\end{array}$ & $\begin{array}{c}\text { Volleyball } \\
(16.52 \pm 4.94)\end{array}$ & $\begin{array}{c}\text { Flying disk } \\
(11.66 \pm 5.27)\end{array}$ & $\begin{array}{l}\text { Table tennis } \\
(7.69 \pm 4.92)\end{array}$ & $\begin{array}{c}\text { T ball } \\
(16.96 \pm 5.51)\end{array}$ & & & \\
\hline \multirow[t]{2}{*}{ MVPA } & Female & $\begin{array}{c}\text { Soccer } \\
(8.19 \pm 3.95)\end{array}$ & $\begin{array}{c}\text { Basketball } \\
(7.18 \pm 3.33)\end{array}$ & $\begin{array}{c}\text { Volleyball } \\
(7.91 \pm 3.43)\end{array}$ & $\begin{array}{l}\text { Flying disk } \\
(9.18 \pm 4.79)\end{array}$ & $\begin{array}{l}\text { Table tennis } \\
(4.16 \pm 3.01)\end{array}$ & $\begin{array}{c}\text { T ball } \\
(11.78 \pm 4.90)\end{array}$ & 39.584 & $.000^{* * *}$ & $\begin{array}{c}\mathrm{T}>\mathrm{S}, \mathrm{B}, \mathrm{V}, \mathrm{F}, \mathrm{t} \\
\mathrm{t}<\mathrm{S}, \mathrm{B}, \mathrm{V}, \mathrm{F}, \mathrm{T} \\
\mathrm{V}>\mathrm{B}\end{array}$ \\
\hline & Total & $\begin{array}{c}\text { Soccer } \\
(10.78 \pm 5.68)\end{array}$ & $\begin{array}{c}\text { Basketball } \\
(9.64 \pm 4.50)\end{array}$ & $\begin{array}{c}\text { Volleyball } \\
(12.61 \pm 6.08)\end{array}$ & $\begin{array}{c}\text { Flying disk } \\
(10.56 \pm 5.20)\end{array}$ & $\begin{array}{l}\text { Table tennis } \\
(5.73 \pm 4.34)\end{array}$ & $\begin{array}{c}\text { T ball } \\
(14.61 \pm 5.83)\end{array}$ & 62.410 & $.000^{* * *}$ & $\begin{array}{l}\mathrm{T}>\mathrm{S}, \mathrm{B}, \mathrm{V}, \mathrm{t} \\
\mathrm{F}>\mathrm{S}, \mathrm{B}, \mathrm{V}, \mathrm{t} \\
\mathrm{t}<\mathrm{S}, \mathrm{B}, \mathrm{V}, \mathrm{F}, \mathrm{T}\end{array}$ \\
\hline
\end{tabular}

S: soccer, B: basketball, V: volleyball, F: flying disk, t: table tennis, T: T ball ${ }^{* * *}<.001$ 
타냈으며, 남학생의 MVPA 참여시간이 여학생에 비해 유 의하게 높은 값을 나타냈다 $(p<.01)$.

종목별 MVPA 차이 분석은 〈Table 5>에 제시되어 있다. 사후 검증 결과, 전체 학생과 남학생의 티볼과 플라잉 디 스크 종목의 MVPA는 축구, 농구, 배구, 탁구 종목에 비해 유의하게 높은 값을 나타냈으며 ( $p<.01)$, 탁구의 MVPA 는 다른 모든 종목들에 비해 유의하게 낮은 값을 나타냈다 ( $p<.01)$. 여학생의 경우, 티볼의 MVPA가 다른 모든 종 목들에 비해 유의하게 높은 값을 나타냈으나 $(p<.01)$, 탁 구의 MVPA는 다른 모든 종목들에 비해 유의하게 낮은 값을 나타냈고 $(p<.01)$, 배구의 MVPA는 농구에 비해 유의하게 높은 값을 나타냈다 $(p<.01)$.

전통 스포츠(축구, 농구, 배구, 탁구)와 뉴스포츠 활동 (티볼, 플라잉 디스크)을 비교한 결과, 여학생의 좌식활동 시간은 남학생에 비해 전통 스포츠와 뉴스포츠 모두에서 유의하게 높은 값을 나타냈다 ( $p$ 〈.001). 전통스포츠와 뉴 스포츠 모두에 있어 여학생의 MVPA 시간은 남학생에 비 해 유의하게 낮은 값을 나타냈다 $(p<.001)$. 남학생의 가 벼운 활동 시간은 전통 스포츠에서 여학생에 비해 유의하 게 높은 값을 나타냈다( $p<.01$ )(Table. 6 참조).

\section{논 의}

\section{체육수업과 MVPA}

체육수업은 청소년기 MVPA의 중요한 영역이지만, 실 제로 체육수업은 요구되는 MVPA를 충분히 제공하지 못
하고 있다(Fairclough \& Stratton, 2005a, 2005b, 2006; Macfarlane \& Kwong, 2003; Pate et al., 2011). 다른 활 동 영역들(움직임 활동, 체력 활동 등)에 비해 MVPA 수 준이 상대적으로 높은 경쟁영역(스포츠 활동)의 MVPA 수 준을 분석한 이 연구에서 역시 $22.89 \%$ (10.26분)에 머물 고 있다. 같은 학교급과 활동 영역을 분석한 국외의 연구들 은 MVPA 수준을 43.2\%(Fairclough \& Stratton, 2005b) 와 35.3\%(Macfarlane \& Kwong, 2003)로 보고하고 있 다. 이렇게 볼 때, 우리나라 체육수업은 국외 체육수업에 비해 저조한 수준의 MVPA 수치를 보이고 있다.

그 이유를 살펴보면, 첫째, 저조한 MVPA 결과는 신체 활동 증진 전략의 투입 여부와 관련된다. 체 육수업 MVPA 실태를 메타 분석한 연구들은 공통적으로 체육수업 $\mathrm{MVPA}$ 수준을 높이기 위해서는 타당한 신체활동 증진 전략이 적 용되어야 한다고 주장한다(Fairclough \& Stratton, 2005b, 2006). 실제로, 청소년의 신체활동 증진 요인을 바탕으로 개 발된 신체활동 증진 프로그램(SPARK, CATCH-PE, LEAP 프로그램 등)을 기반으로 하는 체육수업은 비-처치 집단 에 비해 증가된 MVPA를 보고하고 있으며 (Fairclough \& Stratton, 2005b, 2006), SPARK 프로그램을 적용한 국내 연구에서도 같은 결과가 보고되고 있다(Lee, 2016; Lee et al., 2016; Lee \& Park, 2017). 뿐만 아니라 체력운동 형식의 활동(training-like exercise)이나 신체적으로 적 극적인 연습 활동과 같이 비교적 단순한 활동을 제 공한 수 업에서도 MVPA 증가 효과가 나타나고 있다(Fairclough $\&$ Stratton, 2005b). 이는 교육적 관점에서 신체활동 증 진을 위해 정교하게 개발된 프로그램이 아니라도 단순한 활동만으로도 체육수업의 MVPA는 충분히 증진될 수 있 다는 것을 의미한다. 무엇보다, 체육수업에서는 목표(예,

Table 6. Mean differences of participation time of levels of physical activity between classic and new sports

\begin{tabular}{|c|c|c|c|c|c|}
\hline \multirow{2}{*}{ Type } & \multirow{2}{*}{ Intensity } & \multicolumn{2}{|c|}{$\mathrm{M}( \pm \mathrm{SD})$} & \multirow{2}{*}{$t$} & \multirow{2}{*}{$p$} \\
\hline & & Male & Female & & \\
\hline \multirow{3}{*}{$\begin{array}{l}\text { Cla } \\
(338,337)\end{array}$} & Sedentary & $15.51( \pm 7.97)$ & $20.88( \pm 7.95)$ & -8.773 & $.000^{* * * *}$ \\
\hline & Light & $18.63( \pm 5.30)$ & $17.53( \pm 5.68)$ & 2.615 & $.009^{* *}$ \\
\hline & MVPA & $10.86( \pm 5.50)$ & $6.62( \pm 4.18)$ & 11.281 & $.000^{* * *}$ \\
\hline \multirow{3}{*}{$\begin{array}{l}\text { New } \\
(167,139)\end{array}$} & Sedentary & $10.43( \pm 5.53)$ & $17.56( \pm 7.60)$ & -9.468 & $.000^{* * *}$ \\
\hline & Light & $17.36( \pm 4.12)$ & $17.07( \pm 4.90)$ & .565 & .572 \\
\hline & MVPA & $16.74( \pm 5.22)$ & $9.83( \pm 4.64)$ & 12.127 & $.000^{* * *}$ \\
\hline
\end{tabular}

Cla: Classic sports, New: New sports

${ }^{* *}<.01,{ }^{* * *}<.001$ 
운동 기술, 사회적 및 도덕적 발달, 미적 인식이나 창의성) 에 따른 전략들 간의 충돌 현상, 이를 테면 운동 기술에 초 점을 두는 전략을 투입하면 사회적 및 도덕적 발달이 저해 되는 현상이 나타나지만, 신체활동 증진 전략은 다른 목표 들과 충돌되지 않는다(Sallis \& McKenzie, 1991). 신체적 으로 적극적이면서도 그 외 다른 목표들을 충분히 실현할 수 있다는 것이다(Fairclough \& Stratton, 2005c). 이러 한 측면에서, 신체활동 증진 전략이 투입되지 않은 체육수 업(non-treatment P.E.)이 낮은 MVPA 결과의 원인이라 할 수 있다.

두 번째 원인은 이 연구의 수업이 기능중심모델에 의거 해 설계 및 운영되었다는 데 있다. 청소년 신체활동 요인 을 분석한 연구들은 신체활동 동기를 강조한다. 여러 연구 들은 신체활동 수준이 내적 동기 자원인 자신감(perceived competence)과 즐거움 (enjoyment)에 영향을 받는다고 강 조한다(Kang \& Lee, 2015; Dishman et al., 2004; 2005; Barr-Anderson et al., 2007; Haerens et al., 2014). 특히 체육수업에서 이들 심리적 요인은 할 수 있다(Am I able?) 는 인식을 제 공해 보다 적극적인 신체활동에 참여할 수 있 도록 하며, 그 성과는 건강지식을 기반으로 하는 가치 있다 (Is it worth it?)는 인식보다 더 강력한 요인으로 작용한다 (Fairclough et al., 2012). 반면, 기능중심모형에 의거한 체 육수업은 지나친 교사 의존 성향(Roberts \& Fairclough, 2011)과 일명 기능과 체력을 기반으로 하는 방법적 접근 (a hard masculinized pedagogy)을 시도하는 문제(Light $\&$ Kentel, 2010)로 신체활동 동기 자원을 충분히 제공하 지 못한다. 실제로, Smith et al. (2015)은 남녀 모두 기능 중심수업모형의 동기 변화가 부정적으로 나타나고, MVPA 역시 차이(전술게임모형 >기능중심모형)를 보인다고 주 장한다. 이렇게 볼 때, 본 연구의 결과가 국외의 다른 연구 들에 비해 저조한 MVPA 수치를 보이는 것은 교수.학습 방법을 기능중심모형으로 통제하였기 때문으로 판단된다.

\section{성별과 종목별 차이}

성 $(\mathrm{sex})$ 은 신체활동 수준의 가장 보편적이고 결정적인 요인이다. 학령기 청소년의 신체적 라이프스타일 (physically active lifestyle)을 분석한 연구들은 연령(초등, 중 등, 고등), 시간(학기 중, 방학 중)과 영역(학교영역, 여가 영역 등), 거주 지역(도시, 시골), 개인의 사회경제적 위치 등에 상관없이 여학생의 신체활동 수준이 남학생에 비해
저조하고, 강도가 높을수록 그 차이는 더 커진다고 밝히고 있다(CPPSE, 2013). 체육수업의 신체활동 특성을 분석한 연구들 역시 소수의 연구들을 제외하면, 학교급에 상관없 이 남학생의 MVPA 수준이 높다고 보고한다(Fairclough \& Stratton, 2005a, 2005b, 2006; Macfarlane \& Kwong, 2003; Pate et al., 2011). 이 연구에서도 여학생들은 높은 좌식 비중과 낮은 MVPA 특성을 보인다.

이러한 차이는 첫째, 스포츠 활동에 대한 여학생의 인식 차이에 있기 때문이다. 스포츠 활동은 기본적으로 남성적 인 스포츠 활동으로 인식된다. 실제로, 스포츠 활동에 참여 하는 여학생들은 자신의 여성성이 손상 받는다는 인식을 가지며, 체육수업에서 신체활동에 참여하는 것을 우선순 위에서 뒤로 미루는 경향이 있다(Whitehead \& Biddle, 2008). 둘째, 교수·학습 측면에서, 기능중심모형의 방법적 역시 원인으로 작용한다. 기능중심모형은 기능과 체력을 기반으로 방법적 근간을 삼기 때문에 남학생 위주로 수업 이 운영된다(Light \& Kentel, 2010). 이로 인해, 기능중심 모형에서 여학생들은 자신감이나 즐거움과 같은 신체활동 참여의 심리적 자원을 획득하는데 어려움이 있으며, 여학 생 신체활동의 주요 자원인 사회적 자원을 제 공하지 못한 다(Sallis et al., 2000). 특히 여학생의 신체활동은 체육교 사와의 상호작용 분위기나 관계에 영향을 받지만(Roberts \& Fairclough, 2011; Sallis et al., 2000), 이 모형에서 교 사의 상호작용은 남학생 중심으로 이루어질 뿐만 아니라 (Davis, 2003), 질적 측면에서 칭찬이나 질문, 운동기술에 대한 조언(교정적 피드백) 역시 남학생이 더 많이 받는다 (Brown et al., 1996; Dunbar \& O'Sullivan, 1986). 이와 같이, 종목과 방법의 성별 특성으로 인해 여학생의 MVPA 수준은 상대적으로 저조한 결과를 보인다.

한편, 종목별 MVPA 특성을 살펴보면, 먼저, 남학생의 MVPA 평균 시간은 티볼, 플라잉 디스크, 농구, 배구, 탁구, 축구 순으로, 여학생은 티볼, 배구, 플라잉 디스크, 농구, 축구, 탁구 순으로 나타난다. ANOVA 분석에서도 티볼과 플라잉 디스크는 다른 종목들과 차이를 보이고 있다. 이 러한 결과는 전통 스포츠 활동보다 뉴스포츠 활동이 남녀 모두에서 높은 MVPA 수준을 제 공한다는 것을 말한다.

다음으로, 종목별 남녀 차이를 분석한 결과, 종목의 성 격과 상관없이 남녀 차이가 나타나고 있다. 반면, 국외의 연구들에서는 성 중립적 종목의 남녀 차이는 나타나지 않 거나 비록 소수지만 여학생의 MVPA 수준이 높다고 보고 된다(Fairclough \& stratton, 2005b, 2006). 이에 비해, 
본 연구에서는 일반적으로 여성의 선호도가 높은 배구나 탁구, 그리고 성 중립적인 활동인 뉴스포츠 활동 (플라잉 디스크, T볼) 모두에서 남녀 간의 차이를 보인다. 이는 국 외의 여학생들에 비해 스포츠활동에 대한 경험이 상대적 으로 저조하기 때문으로 판단된다. 일례로, 미국 여학생의 86\%는 학교 밖에서 구조화된 신체활동(즉 스포츠 활동) 에 정기적으로 참여하는 반면(Barr-Anderson et al., 2007), 학교 외에서 체육활동에 참여하는 우리나라 10 대 청소년 의 비율은 불과 $19.1 \%$ 에 머물고 있다(MCST, 2017). 대 개 남자 청소년의 참여율이 더 높다고 할 때, 여자 청소년 의 학교 밖 신체활동은 참여율은 더 저조할 것으로 판단 된다.

\section{결론 및 제언}

본 연구에서는 3 차원 가속도계를 활용해 경쟁영역 체 육수업의 신체활동 수준을 성과 종목에 따라 측정하였다. 연구 결과, 첫째, 경쟁영역 체육수업의 MVPA 수준은 $28.58 \%$ (12.8분)으로 나타났다. 둘째, 남학생의 MVPA 수준(12.80분)은 여학생 (7.56분)에 비해 유의하게 높게 나타났으며, 모든 종목 및 전통스포츠와 뉴스포츠 간에서 도 남녀 차이가 유의하게 나타났다(남학생 >여학생). 셋 째, 종목별 MVPA를 비교한 결과, 티볼과 플라잉 디스크가 다른 종목들에 비해 유의하게 높고, 탁구는 유의하게 낮은 것으로 나타났다. 결론적으로, 경쟁영역 체육수업의 $\mathrm{MVPA}$ 수준은 체육수업 MVPA 권장 기준을 충족하지 못하고 있 다. 따라서 신체적으로 적극적인 체육수업 및 남녀 차이를 극복하기 위한 교육적 대안이 마련될 필요가 있다.

마지막으로, 향후 연구 주제를 제안하면, 첫째, 학습자 특성을 고려해 기능 수준이나 체중 상태에 따른 분석이 요 청된다. 둘째, 활동 종목 측면(예, 체력운동, 육상이나 체 조, 무용 등)에서 확장된 연구가 필요하다. 셋째, 체육수업 에서 MVPA가 높은 학생과 낮은 학생의 심리적·사회적 특 성을 비교하는 연구가 요청된다.

\section{참고문헌}

ACSM (American College of Sports Medicine) (2014). ACSM's Guidelines for Exercise Testing and Prescription 9th ed..
Philadelphia, PA: Lippincott Williams \& Wilkins.

Arnett, M. G., \& Lutz, R. B. (2003). Measurement of moderate to vigorous physical activity of middle school girls, using Tritrac activity monitors during small-sided, game-based lessons. Measurement in Physical Education and Exercise Science, 7(3), 149-159.

Bailey, R. (2006). Physical education and sport in schools: A review of benefits and outcomes. Journal of School Health, 76(8), 397-401.

Barr-Anderson, D. J., Young, D. R., Sallis, J. F., NeumarkSztainer, D. R., Gittelsohn, J., Webber, L., ... \& Jobe, J. B. (2007). Structured physical activity and psychosocial correlates in middle-school girls. Preventive medicine, 44(5), 404-409.

Brown, S., Brown, D., \& Hussey, K. (1996). Promote equality in the classroom. Strategies, 9(6), 19-22.

Castelli, D. M., Carson, R. L., \& Kulinna, P. H. (2014). Special issue: Comprehensive school physical activity programs. Journal of Teaching in Physical Education, 33(4), 435-439.

Choi, E. (2001). Qualitative research in Sport Pedagogy: A literature review. Korean Journal of Sport Pedagogy, 8(1), 25-58.

CPPSE (Committee on Physical Activity and Physical Education in the School Environment) (2013). Educating the Student Body: Taking Physical Activity and Physical Education to School. Washington, D.C.: The National Academic Press.

Dale, D., Corbin, C. B., \& Dale, K. S. (2000). Restricting opportunities to be active during school time: do children compensate by increasing physical activity levels after school? Research Quarterly for Exercise and Sport, 71(3), 240-248.

Davis, K. L. (2003). Teaching for gender equity in physical education: A review of the literature. Women in Sport and Physical Activity Journal, 12(2), 55-81.

Dishman R. K., Motl R.W., Saunders R, Felton, G., Ward, D. S., Dowda, M., \& Pate, R. R. (2005). Enjoyment mediates effects of a school-based physical-activity intervention. Medicine and Science in Sports and Exercise, 37(3), 478-487.

Dishman, R. K., Motl, R. W., Saunders, R., Felton, G., Ward, D. S., Dowda, M., \& Pate, R. R. (2004). Self-efficacy partially mediates the effect of a school-based physical-activity intervention among adolescent girls. Preventive Medicine, $38,628-636$.

Dunbar, R. R., \& O'Sullivan, M. M. (1986). Effects of intervention on differential treatment of boys and girls in elemen- 
tary physical education lessons. Journal of Teaching in Physical Education, 5(3), 166-175.

Fairclough, S. J. (2003). Girls' physical activity during high school physical education: Influences of body composition and cardiorespiratory fitness. Journal of Teaching in Physical Education, 22(4), 382-395.

Fairclough, S. J., \& Stratton, G. (2006). A review of physical activity levels during elementary school physical education. Journal of teaching in physical education, 25(2), 240-258.

Fairclough, S., \& Stratton, G. (2005a). Physical activity levels in middle and high school physical education: A review. Pediatric Exercise Science, 17(3), 217-236.

Fairclough, S., \& Stratton, G. (2005b). 'Physical education makes you fit and healthy'. Physical education's contribution to young people's physical activity levels. Health Education Research, 20(1), 14-23.

Fairclough, S., \& Stratton, G. (2005c). Improving healthenhancing physical activity in girls' physical education. Health Education Research, 20(4), 448-457.

Fairclough, S., Hilland, T., Stratton, G., \& Ridgers, N. (2012). 'Am I able? Is it worth it?' Adolescent girls' motivational predispositions to school physical education: Associations with health-enhancing physical activity. European Physical Education Review, 18(2), 147-158.

Gavarry, O., Bernard, T., Giacomoni, M., Seymat, M., Euzet, J. P., \& Falgairette, G. (1997). Continuous heart rate monitoring over 1 week in teenagers aged 11 - 16 years. European Journal of Applied Physiology and Occupational Physiology, 77(1-2), 125-132.

Griggs, G. (2012). Why have alternative sports grown in popularity in the UK? Annals of Leisure Research, 15(2), 180-187.

Haerens, L., Kirk, D., Cardon, G., De Bourdeaudhuij, I., \& Vansteenkiste, M. (2014). Motivational profiles for secondary school physical education and its relationship to the adoption of a physically active lifestyle among university students. European Physical Education Review, 16(2), 117139.

Kang, H. K. \& Lee, G. I. (2015). Levels and areas of physically active lifestyle among Korean middle school students and relationships to physical self-efficacy. Korean Journal of Sport Science, 26(4), 904-916.

Kim, H. W. (2010). Comparison of Classes Participation Factor and Satisfaction on the New Sports and Traditional PE Classes. The Korean Journal of Physical Education, 49(6), 323-334.
Kim, N. K. (2009). A research on application of coed physical education class in new sports: Focusing on students' responses. Korean Journal of Sport Pedagogy, 16(3), 17-34.

Kirk, D. (2010). Physical Education Futures. London: Taylor \& Francis Group.

Lee, G. I. \& Park, J. Y. (2017). The effect of SPARK M-SPAN based physical education curriculum(1 year) on amount of MVPA and health related fitness in middle school students. The Korean Journal of Physical Education, 56(1), 713-726.

Lee, G. I. (2016). Analysis of Moderate to Vigorous Physical Activity Effects and Causes of SPARK M-SPAN Fitness Program: Sequential Mixed Method. Korean Journal of Sport Science, 27(4), 861-877.

Lee, G. I., Shin, M. C., \& Park, J. Y. (2016). Promotional effect of physical activity of SPARK M-SPAN program based track \& field lessons in middle school. The Korean Journal of Physical Education, 55(5), in press.

Lee, M. Y. (2012). Criterion and Convergent Validity Evidences of an Accelerometer and a Pedometer. Korean Journal of Measurement and Evaluation in Physical Education and Sports Science, 14(2), 1-13.

Light, R., Kentel, J., Kehler, M., \& Atkinson, M. (2010). Soft pedagogy for a hard sport: Disrupting hegemonic masculinity in high school rugby through feminist-informed pedagogy. In M. Kehler, \& M. Atkinson (Eds.), Boys' Bodies: Speaking the Unspoken (pp. 133-154). New York: Peter Lang Publishing, Inc.

Macfarlane, D., \& Kwong, W. T. (2003). Children's heart rates and enjoyment levels during PE classes in Hong Kong primary schools. Pediatric Exercise Science, 15(2), 179-190.

McClain, J. J., Abraham, T. L., Brusseau Jr., T. A., \& TudorLocke, C. (2008). Epoch length and accelerometer outputs in children: comparison to direct observation. Medicine and Science in Sports and Exercise, 40(12), 2080-2087.

McKenzie, T. L. (2001). Promoting physical activity in youth: focus on middle school environments. Quest, 53(3), 326-334.

MCST(Ministry of Culture, Sports and Tourism)(2017). 2017 Survey on Participation in Physical Activity in National Life. Seoul: Ministry of Culture, Sports and Tourism.

Metzler, M. (2017). Instructional models in physical education 3rd edition. New York: Routledge.

NASPE (National Association for Sport and Physical Education) (2005). Is it physical education or physical activity? NASPE position statement. Strategies, 19(2), 33-34. 
PAGAC (Physical Activity Guidelines Advisory Committee) (2008). Physical activity guidelines advisory committee report. Washington, DC: HHS.

Pate, R. R., O’Neill, J. R., \& McIver, K. L. (2011). Physical activity and health: does physical education matter? Quest, 63(1), 19-35.

Roberts, S., \& Fairclough, S. (2011). Observational analysis of student activity modes, lesson contexts and teacher interactions during games classes in high school (11-16 years) physical education. European Physical Education Review, $17(2), 255-268$.

Sallis, J. F., \& McKenzie, T. L. (1991). Physical education's role in public health. Quarterly for Exercise and Sport, 62, 124137.

Sallis, J. F., Prochaska, J. J., \& Taylor, W. C. (2000). A review of correlates of physical activity of children and adolescents. Medicine and science in sports and exercise, 32(5), 963-975.

Scantling, E., Dugdale, H., Bishop, P., Lackey, D., \& Strand, B. (1998). The effects of two instructional formats on the heart rate intensity and skill development of physical education students. Physical Educator, 55(3), 138.

Smith, L., Harvey, S., Savory, L., Fairclough, S., Kozub, S., \& Kerr, C. (2015). Physical activity levels and motivational responses of boys and girls: A comparison of direct instruct- ion and tactical games models of games teaching in physical education. European Physical Education Review, 21(1), 93-113.

Strand, B., \& Anderson, C. (1996). A comparison of two instructional formats on heart rate intensity, skill achievement and student attitude. Neb. J. Health Phys. Educ. Recreat. Dance, 27, 21-24.

Strong, W. B., Malina, R. M., Blimkie, C. J., Daniels, S. R., Dishman, R. K., Gutin, B., Hergenroeder, A. C., Must, A. Nixon, P. A., Pivarnik, J. M., Rowland, T., Trost, S., \& Trudeau, F. (2005). Evidence based physical activity for school-age youth. The Journal of Pediatrics, 146(6), 732-737.

Trost, S. G., \& Loprinzi, P. D. (2008). Exercise-Promoting healthy lifestyles in children and adolescents. Journal of Clinical Lipidology, 2(3), 162-168.

Tudor-Locke, C., Craig, C. L., Aoyagi, Y., Bell, R. C., Croteau, K. A., De Bourdeaudhuij, I., \& Lutes, L. D. et al. (2011). How many steps/day are enough? For older adults and special populations. Int J Behav Nutr Phys Act, 8(1), 80-99.

Welk, G. (2002). Physical activity assessments for healthrelated research. Human Kinetics.

Whitehead, S., \& Biddle, S. (2008). Adolescent girls' perceptions of physical activity: A focus group study. European Physical Education Review, 14(2), 243-262. 


\section{3 차원 가속도계를 활용한 체육수업의 중-고강도 신체활동 수준 분석: 경쟁영역을 중심으로 \\ 이규일(경북대학교)}

〔목적〕 본 연구의 목적은 3차원 가속도계를 활용해 경쟁영역 체육수업의 중-고강도 신체활동 특성을 성과 종목 측면에서 파악하는 것이다. 〔방법〕 6개 종목(축구, 농구, 플라잉 디스크, 배구, 탁구, 티볼)으로 운영된 체육수업에 참가한 남녀 중학생 981명 (남학생 505명, 여학생 476명)을 연구 대상자로 삼았다. 수업은 기능 중심모형으로 통제되었으며, 신체활동 자료는 3 차원 가속도계를 활용해 수집되었으며, 자료의 성별 분석을 위 해 t 테스트 검정〈.05)과 종복별 비교를 위해 ANOVA 분석(<.05)을 실시하였다. 〔결과) 첫째, 운동강도별 신체활동의 시간을 기술통계 분석한 결과, 체육수업의 MVPA는 평균 10.26 분 $(22.89 \%)$ 로 나타났으며, 종목 별로는 티볼(14.61분), 플라잉 디스크(12.61분), 축구(10.78분), 배구(10.56분), 농구(9.64분), 탁구(5.73 분) 순으로 나타났다. 둘째, 성별 분석 결과, 여학생의 MVPA는 모든 종목에서 남학생에 비해 유의미하게 낮 은 결과를 보였다. 또한 전통스포츠와 뉴스포츠에서도 같은 결과를 보였다. 셋째, 종목별 사후 검증 결과, 티볼 은 다른 모든 종목들에 비해 유의하게 높은 MVPA 값을 보인 반면, 탁구는 다른 모든 종목들에 비해 유의하게 낮은 값을 나타냈다 (.000). (결론) 국내 체육수업의 MVPA 수준은 MVPA 권장량을 달성하지 못하였고, 동 일 학교급과 활동 종목을 분석한 국외 연구들에 비해 저조한 것으로 확인되었다. 또한 모든 종목에서 남녀 차 이가 나타났으며, 종목의 특성에 따라 뉴스포츠 활동이 근대스포츠 활동보다 MVPA 수준이 높게 나타났다. 이러한 결과는 체육수업의 MVPA 증진과 남녀 차이를 극복하기 위한 대안 마련이 시급함을 시사해 준다.

주요어: 체육교육, 여학생, 경쟁영역, 중-고강도 신체활동, 3 차원 가속도계 